\title{
Effect of Sociodemographic Factors and Multidimensional of Risk Toward Financial Risk Tolerance and Risk Tolerance Assessment Using Data Envelopment Analysis of Indonesian Investors
}

\author{
Irna Puji Lestari \\ Ministry Religious Affairs of Indonesia, Jakarta Regional Office, Indonesia \\ DOI - http://doi.org/10.37502/IJSMR.2021.4407
}

\begin{abstract}
Understanding individual risk tolerance before making an investment decision is very important. The different characteristics of investors result in different levels of risk tolerance, hence considering investor's sociodemographic factors is very important in assessing individual risk tolerance. This study aims to investigate factors affecting financial risk tolerance such as sociodemographic factors and multidimensional risk. This study was conducted on 438 Indonesian investors through an online survey. The results showed that sociodemographic factors such as age, gender, marital status, education, and income had an effect on financial risk tolerance, whereas ethnics do not have an effect on financial risk tolerance. This study also found that multidimensional risk had an effect on risk tolerance and be the potential mediator between sociodemographic factors and financial risk tolerance. This study also considers Data Envelopment Analysis (DEA) to assess investor risk profile. DEA scores show that most Indonesian investors tend to have less risk tolerance.
\end{abstract}

Keywords: Risk Tolerance, Risk Attitude, Risk Capacity, Sociodemographic Factors, Multidimensional of risk, Data Envelopment Analysis.

\section{Introduction}

Every investment is exposed to a different type of risk. Often, it is hard to really know what risk that investors are comfortable with until they have experienced losses. Sometimes investors were more reluctant to take big risks as there was a lot of uncertainty in the market or the risk threshold that may change at different stages in their life. It is therefore important for all investors to determine the level of risk they are willing to take. Once investors know how much risk they can tolerate, they can make the best investment decision that is suitable with their risk profile. Thus, financial risk tolerance is a key element and plays an important role to consider in making investment decisions to achieve financial goals for both investors and investment managers (Anbar and Eker, 2010).

Risk tolerance is generally defined as the maximum amount of uncertainty someone is willing to accept when making a financial decision (Grable and Joo, 2004). Risk tolerance is also an underlying factor within financial planning models, investment suitability analyses, and consumer decision frameworks (Grable, 2008). A more inclusive definition of risk tolerance is the extent to which a person chooses to risk experiencing a less favorable outcome for the chance of a more favorable outcome (Roszkowski et al., 2005). However, Cordell (2001) provides a specific model for risk tolerance as a multidimensional construct: 
risk propensity, risk attitude, risk capacity, and risk knowledge. Cordell (2001) suggests that in order to truly understand an investor's financial risk tolerance, this multidimensional risk must be measured separately. Further research by Cordell (2002) suggested that financial risk tolerance could be usefully viewed in just two dimensions; risk attitudes and risk capacity. Cordell $(2001,2002)$ defines risk attitude as the amount of risk one chooses to incur, whereas risk capacity is how much risk one can afford to incur.

Moreover, it is very important to be mindful of the fact that financial risk tolerance may differ from one person to another based on their demographic feature (Subramaniam and Athiyaman, 2016). Many previous studies have examined sociodemographic factors affecting financial risk tolerance using variables such as age (Pålsson, 1996; Grable and Lytton, 1998; Hallahan, Faff and McKenzie, 2004), gender (Bajtelsmit and Bernasek, 1996; Pålsson 1996; Roszkowski and Grable, 2005), marital status (Grable and Joo, 2000; Roszkowski, Snelbecker, and Leimberg, 1993; Sung and Hanna, 1996), education (Sung and Hanna, 1996; Grable, 2000; Hallahan, Faff and McKenzie, 2004), income (Riley and Chow, 1992; Grable and Lytton, 1999; MacCrimmon and Wehrung (1986), and ethnicity (Ogden, Ogden, and Schau, 2004; Dilworth-Anderson, Burton and Johnson, 1993). There is general agreement among investment managers and researchers that demographic factors can be used to differentiate and classify risk tolerance levels of investors into categories (Anbar and Eker, 2010).

Furthermore, recent research by Ardehali, Paradi, and Asmild (2005) proposed a new method of assessing financial risk tolerance through Data Envelopment Analysis (DEA). Using this application of DEA, the most risk-tolerant individuals will construct the frontier. Other individuals will be enveloped by the frontier and their distance from it indicates their relative risk tolerance. Those who are most risk-averse will be located at the farthest from the frontier (Ardehali et al., 2005).

Based on the previous studies, there is a gap in examining financial risk tolerance that has not considered the influence of sociodemographic factors partially and simultaneously with multidimensional risk. Meanwhile, based on The Indonesia Central Securities Depository (KSEI), the current demographic data of Indonesian investors show that it is dominated by men (59.41\%), age 21-30 (44.62\%), who are Private Sector Employees (53.69\%) with Bachelor degrees (48.23\%) (KSEI, 2019). Therefore, our study focuses on investor risk tolerance in Indonesia, and in particular, how these sociodemographic factors influence their risk tolerance. Given that risk tolerance is a multifaceted construct, thus multidimensional risk should be a determinant level of risk tolerance. The multidimensional risks in this study are risk attitude and risk capacity. We will also examine whether the DEA can be applied to assess risk tolerance in Indonesia.

Based on the background that has been described, the research problem is explained in the form of research questions as follows:

1. Do sociodemographic factors affect the financial risk tolerance of Indonesian investors?

2. Do multidimensional risk affect the financial risk tolerance of Indonesian investors?

3. Do sociodemographic factors affect multidimensional risks?

4. Do sociodemographic factors affect the financial risk tolerance of Indonesian investors mediated by the multidimensional risks?

5. Do Data Envelopment Analysis (DEA) able to show financial risk tolerance of Indonesian investors?

\section{Literature Review and Hyphothesis Development}




\section{Risk Tolerance}

Risk tolerance is the inverse of risk aversion, which is an economic term that depicts a person's hesitancy to accept a choice that has an uncertain payoff when an alternative choice with a more certain outcome is available (Grable, 2016). Within the domain of financial decision-making, financial risk tolerance is generally defined as the maximum amount of uncertainty someone is willing to accept when making financial decisions (Grable and Joo, 2004). Financial risk tolerance also affects the way people invest their resources for shortand long-term goals, such as saving for a significant purchase and retirement. It is reasonable to expect that people with varying levels of risk tolerance should act differently when making investment decisions, with those having a high-risk tolerance (i.e., low aversion to risk) investing more aggressively (Grable, 2016). Because a person's tolerance for risk has such a significant impact on the way individuals make decisions, it is important to have a conceptual understanding of the factors that influence risk tolerance (Campbell, 2006). There are a number of demographic, socioeconomic, psychosocial, and other factors generally thought to be associated with financial risk tolerance (Grable, 2016), and also multidimensional nature of risk

\section{Factors Affecting Financial Risk Tolerance}

\section{Sociodemographic Factors}

Each investor has his own level of financial risk tolerance depending on several factors. There is a consensus among practitioners that demographic factors could be used to differentiate and classify individual investors. This classification could help them to develop a better financial strategy for their clients (Chang et al., 2004). Result study from Chang et al. (2004) indicates that age, education, race, employment, and subjective risk tolerance are influential in choosing the type of assets for investments. Financial advisors are encouraged to find ways to enhance their relationship with under-served audiences such as younger clients, minorities, and those with less education.

Grable and Lytton (2001) review seventeen studies that measure risk tolerance and report that gender, marital status, wealth, education, ethnicity, and age are related to risk tolerance. Their review of research shows that respondents with higher risk tolerance are more likely to invest in stocks within a retirement plan, save more, are more likely to achieve retirement adequacy and that investment in risky assets is related to risk tolerance.

Praba (2016) investigate the association between the sociodemographic factors and the financial risk tolerance level of individual investors and his study reveals that age, gender, and income has a significant association with the financial risk tolerance of individual investors. The investment products should be designed in such a way that it is catered to select individual investors with varying risk profile (Praba, 2016)

\section{Multidimensional of Risk}

Research by Cordell (2002) found that financial risk tolerance can be measured in two dimensions; risk attitudes and risk capacity. Risk attitude refers to the willingness to incur monetary risk (Cordell, 2001). Furthermore, Cordell (2001) states that risk attitudes are the characteristics that most people probably think of when they talk about risk tolerance. Cordell (2002) measures risk attitude with items such as ranking investment objectives, allocating a make-believe windfall among various specified investment alternatives, revealing the level of 
thrill or anxiety felt after making financial decisions, selecting the preferred risk/return tradeoff.

Risk capacity refers to individual financial ability to incur risks (Cordell, 2002). Risk capacity is also defined as how much risk a client can afford (Brayman, 2012). Capacity for risk can be determined somewhat objectively, based on the individual's income, age, financial stability, family situation, and similar quantifiable factors. Tolerance for risk is more of an attitudinal measure and is thus more subjective than risk capacity (Bosner and Lakehal-Ayat, 2008). Cordell (2001) measuring risk capacity with items such as portfolio goals and constraints, income, expenses, balance sheet, financial obligations, and insurance coverage.

\section{Hypothesis Development}

\section{Sociodemographic and Financial Risk Tolerance}

Age is the most investigated demographic factor related to risk tolerance. Older individuals tend to be less risk-tolerant than younger individuals, probably because older individuals have less time to meet their goals and objectives (John Grable and Lytton, 1999). Most research found that financial risk tolerance decreases with age (Pålsson, 1996; Grable and Lytton, 1998; Hallahan, Faff, and McKenzie, 2004). Contrary to this, Wang and Hanna (1998) find a positive relationship between age and financial risk tolerance. Young people may appear more risk-averse since it is hard for them to endure any short-term investment losses with limited financial resources (Wang and Hanna, 1998).

Many studies have also revealed that women have lower risk tolerance than men (Bajtelsmit and Bernasek, 1996; Pålsson 1996; Roszkowski and Grable, 2005; Fisher and Yao, 2017). This difference is attributed to a personality trait in men referred to as "thrill-seeker or sensation seeker" (Roszkowski et al., 1993). Women accumulate less wealth than men over time. It may be primarily due to women's lower risk tolerance (Roszkowski and Grable, 2005).

Some research also supports that marital status affects financial risk tolerance as married couples tend to have more responsibilities than a single person (Roszkowski et al., 1993). Therefore, they are less risk-tolerant than single persons (Sung and Hanna, 1996; Hallahan et al., 2004; Roszkowski et al., 1993). Furthermore, it is believed that married couples have more financial commitments and a larger number of dependents (Kannadhasan, 2015), thus they feel more responsible for any losses on risky investments (Ardehali et al., 2005). Contrary to this, Grable (2000) found that married couples were more risk-tolerant than single persons. Married couples have a tendency to take greater risks because they share more income and double capital from individuals married who might encourage them to invest in risk assets (Grable, 2000)

Previous research also found a positive relationship between education and financial risk tolerance (Sung and Hanna, 1996; Grable, 2000; Hallahan, Faff, and McKenzie, 2004). People with professional education have a better ability to assess risk and return of an investment than others (Kannadhasan, 2015). Investors with a higher level of education and experience have more understanding of various investment options and their features. They also have knowledge in managing the risk by using various techniques (Subramaniam and Athiyaman, 2016).

According to MacCrimmon and Wehrung (1986), people with higher income levels and millionaires usually take greater risks than people with low income. The wealthier person can more easily afford to absorb the losses resulting from a risky investment (Ardehali et al., 2005). Therefore, there is a positive relationship between income and the level of risk 
tolerance (Riley and Chow, 1992; Grable and Lytton, 1999). People with higher income may be more conservative with their money while people with less income may see the risky investment as an opportunity to make a fortune.

Ogden, Ogden, and Schau (2004) suggest that subcultures, which can be represented by race or ethnicity, will influence preferences of risk. Ethnic represents the history and shared values of a group and, as such, must influence financial preferences. Differences in cultural values and socialization between different racial or ethnic groups will also influence preferences such as risk aversion and willingness to take risks (Dilworth-Anderson et al., 1993). Thus, ethnicity can be considered a determinant of risk tolerance.

Based on the previous study and conceptual framework mentioned above, we assume that sociodemographic factors affects investor risk tolerance, thus, the proposed hypothesis is as follows:

H1a: There is an effect of age on financial risk tolerance

$\mathrm{H} 1 \mathrm{~b}$ : There is an effect of gender on financial risk tolerance

H1c: There is an effect of of education level on financial risk tolerance

H1d: There is an effect of marital status on financial risk tolerance

H1e: There is an effect of income on financial risk tolerance

H1f: There is an effect of ethnic on financial risk tolerance

\section{Multidimensional of Risk and Financial Risk Tolerance}

Based on Cordell (2002) two dimensions of risk, risk attitudes, and risk capacity are related to financial risk tolerance. Some researchers define risk attitude as risk-taking behavior (Weber et al., 2002; Lampenius and Zickar, 2005; Kannadhasan, 2015). An individual who is willing to take risks tends to exhibit high risk-taking behavior (Kannadhasan, 2015). Therefore, risk attitude has a positive relationship with risk tolerance. Faff, Mulino, and Chai (2006) tested the relationship of risk attitude which is proxied as risk aversion to financial risk tolerance through online lottery selection experiments. The study results that risk tolerance and risk attitude have a positive relationship. In general, it was determined that persons who were categorized as having low-risk tolerances tended to be less confident in their investment behaviors, less aggressive in their investing behaviors, and more likely to avoid risky financial situations than those who were categorized into higher risk-tolerance categories (Grable and Lytton, 2001).

Gutter (2000) using data obtained from the Survey of Consumer Finances, found that over $86 \%$ of the households who do not own risky assets should have high objective risk capacity. While risk capacity is all about the financial aspects of an individual's ability to sustain risk, risk tolerance measures the abstract ability of individuals to deal with risk emotionally, or behaviorally. Two individuals might have identical incomes, ages, etc, and therefore have the identical capacity for risk. But it would not be surprising to find that one of them can tolerate more risk, despite the similarity of their situations (Bosner and Lakehal-Ayat, 2008). Thus, there is a relationship between risk capacity and risk tolerance.

Based on the previous study and conceptual framework mentioned above, we assume that multidimensional risks affect investor risk tolerance, thus, the proposed hypothesis is as follows:

$\mathrm{H} 2 \mathrm{a}$ : There is an effect of risk attitude on financial risk tolerance

$\mathrm{H} 2 \mathrm{~b}$ : There is an effect of risk capacity on financial risk tolerance 


\section{Sociodemographic Factors and Multidimensional of Risk}

Age and gender are natural factors that can differentiate a person's behavior, therefore age and gender among other sociodemographic factors, are the most likely to influence risk attitude. This prediction support by Hallahan et al. (2004) which state that risk attitudes decrease as age increases. While Barber and Odean (2001) state that risk attitudes are lower for women than men. A previous study from Kannadhasan (2015) found that women have lower risk behaviors than men. Women have a longer life expectancy, show greater responsibility for their families, and have lower lifetime income potential, and so on. This emphasizes the need for women to be educated to enable them to use risk wisely in ensuring adequate results to meet their financial needs.

Zanella (2015) states that risk capacity depends primarily on total wealth, which is composed of two parts: financial resources and human capital. Financial resources can be proxied with income, and human capital can be proxied with working life or age. In general, those in the financial field believe that younger people have an objectively high-risk capacity because of their traditionally low ratios of financial assets to total wealth (Zanella, 2015). Besides that, higher-income individuals have enough resources to meet essential commitments. Since they invest surplus money they have a greater capacity to incur risk (O'Neill, 1996). Thus, we can assume that age and income are related to risk capacity. However, there is not much finding of the relationship between other factors of sociodemography such as gender, education, marital status, and ethnic to risk capacity.

Based on the previous study and conceptual framework mentioned above, we assume that sociodemographic factors such as age and gender affects the multidimensional risk namely risk attitudes, then, for risk capacity, the sociodemographic factors affecting are age and income. Thus, the proposed hypothesis is as follows:

$\mathrm{H} 3 \mathrm{a}$ : There is an effect of age on risk attitude

$\mathrm{H} 3 \mathrm{~b}$ : There is an effect of gender on risk attitude

$\mathrm{H} 3 \mathrm{c}$ : There is an effect of age on risk capacity

$\mathrm{H} 3 \mathrm{~d}$ : There is an effect of income on risk attitude

\section{Sociodemographic Factors, Multidimensional of Risk and Risk Tolerance}

Young people have a different attitude from older people, likewise when they facing risks. Younger people should invest a relatively larger fraction of their wealth in stocks, diversifying their total wealth, independently of their degree of risk attitude (Zanella, 2015). As individuals age, they prefer to invest in less risky assets and high saving rates for retirement, hence, they are more risk-averse and become less risk-tolerant. Whereas for gender, there is a common belief that women are more risk-averse than men (Bajtelsmit and Bernasek, 1996). A study by Cooper et al. (2014) found that women's risk attitudes are lower than men's. Women's attitude toward risk is also influenced by their risk tolerance. Hence, we can assume that risk attitude mediated the effect between gender and age on risk tolerance.

Young workers should have a relatively high-risk capacity because their wealth is mainly composed of human capital; that is, the present value of future labor income (or savings) (Zanella, 2015), and to maintain a constant exposure to risk, they should have high-risk tolerance to invest in risky assets. Hence, age, however, can affect completely someone's risk tolerance if they have risk capacity. Likewise, income will have a greater effect on risk tolerance if balanced with high-risk capacity. Income uncertainty leads individuals who can face liquidity constraints or insurance markets that are imperfect to save a target level of 
wealth (derived from their risk exposure, risk aversion, and time preference) as a buffer stock against bad income shocks (Zanella, 2015).

Based on the previous study and conceptual framework mentioned above, we assume that multidimensional risk mediated the effect of sociodemographic factors to risk tolerance. Thus, the proposed hypothesis is as follows:

H4a: There is an effect of age on risk tolerance mediated by risk attitude

$\mathrm{H} 4 \mathrm{~b}$ : There is an effect of gender on risk tolerance mediated by risk attitude

$\mathrm{H} 4 \mathrm{c}$ : There is an effect of age on risk tolerance mediated by risk capacity

H4d: There is an effect of income on risk tolerance mediated by risk attitude

\section{Financial Risk Tolerance and Data Envelopment Analysis}

Data Envelopment Analysis (DEA) was introduced by Charnes et al. (1978). DEA is a nonparametric linear optimization technique typically used to measure the efficiency of a set of comparable production units which use the same set of inputs to produce the same set of outputs. Ardehali et al. (2005) first introduce Data Envelopment Analysis to risk tolerance assessment approaches. They consider using the Slack-Based Model (SBM) developed by Tone (2009) or known as SBM-DEA. The results from applying this model to the available psychometric data were very encouraging since they show a high correlation with scores obtained by the data owners (Ardehali et al., 2005). Slack Based Model is formulated as follows:

$$
\begin{aligned}
& \text { minimize } \rho_{0}= \frac{1-\frac{1}{m} \sum_{i=1}^{m} s_{i}^{-} / x_{i o}}{1+\frac{1}{s} \sum_{r=1}^{s} s_{r}^{+} / y_{i o}} \\
& \text { Subjectto }= \sum_{j=1}^{n} x_{i j} \lambda_{j}+s_{i}^{-}=x_{i o}(i=1, \ldots, m) \\
& \sum_{j=1}^{n} y_{r j} \lambda_{j}-s_{r}^{+}=y_{r o} \quad(r=1, \ldots, s) \\
& \lambda_{j} \geq 0 \quad(j=1, \ldots, n) \\
& s_{i}^{-} \geq 0 \quad(j=1, \ldots, m) \\
& s_{r}^{+} \geq 0 \quad(r=1, \ldots, s) \\
& 0 \leq \rho_{0} \leq 1 \rho_{0}
\end{aligned}
$$

Where

$\mathrm{j} \quad=$ the index for $n$ individuals

$\mathrm{i}=$ the index for $m$ risk inhibitors

$\mathrm{r} \quad=$ the index for $s$ risk enablers

$\boldsymbol{x}_{\boldsymbol{i} j}=$ the value that individual $j$ has specified for risk inhibitor $i$

$\boldsymbol{y}_{\boldsymbol{r} \boldsymbol{j}}=$ the value that individual $j$ has specified for risk enabler $r$

$\boldsymbol{s}_{\boldsymbol{i}}^{-}=$the amount individual $o$ exceeds the value of risk inhibitor $i$ relative to its riskiest peers

$\boldsymbol{s}_{\boldsymbol{r}}^{+}=$the amount individual $o$ is short on the value of risk enabler $r$ relative to its riskiest peers

$\lambda_{j}=$ the weight of individual $j$ as a peer for individual $o$

$\rho_{0}=$ risk score for individual $o$

Following Ardehali et al. (2005) all the questions used in this study are oriented such that higher choice values are indicative of higher risk tolerance, then they are all classified as 
outputs. For the input, based on Ardehali et al. (2005), we provide one additional question called Unity input.

In the risk tolerance context, individual investors can be considered as the DMUs and the "efficiency" that is being measured is their risk tolerance. DEA scores each individual between 0 and 1, where a value of one indicates that the person is the most willing to take risks whereas the lowest values indicate the most risk-averse individuals (Ardehali et al., 2005).

Therefore, we assume that the DEA can be applied to measure the risk tolerance score of Indonesian investors. Thus, the hypothesis is as follows:

H5: Data Envelopment Analysis (DEA) shows that most Indonesian investors tend to have high financial risk tolerance $($ score $=1)$.

Based on the development of hypotheses that have been proposed, the model in this study is divided into two models shown in Figure 1 and Figure 2.

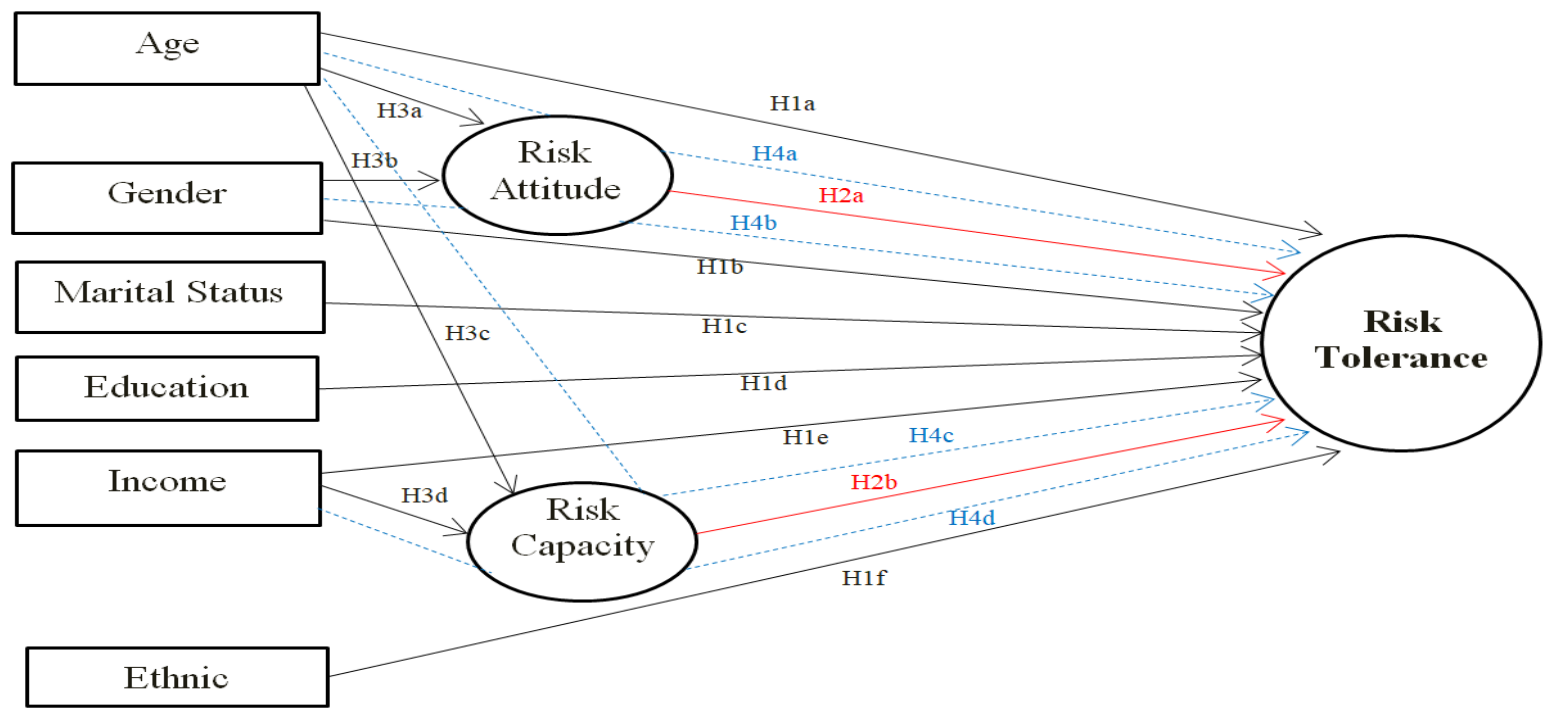

Figure 1. Model 1

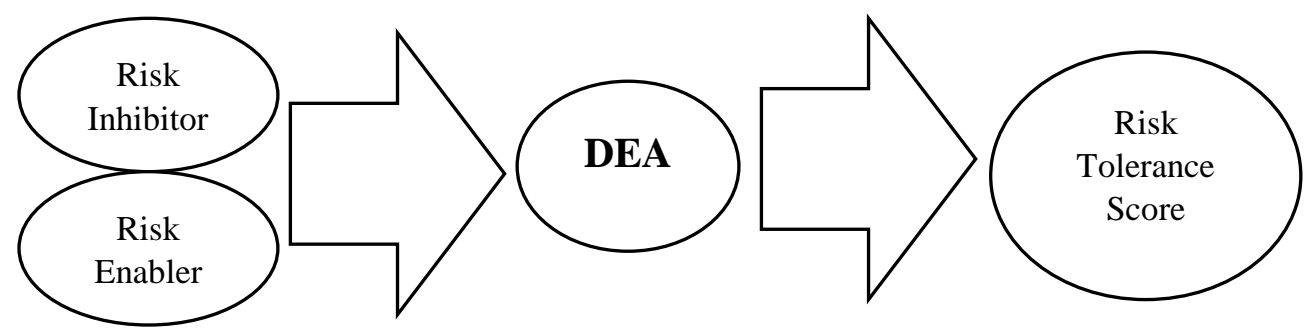

Figure 2. Model 2

\section{Methodology}

This study covers six independent variables namely age, gender, marital status, education, income, and ethnicity; two mediating variables namely risk attitudes and risk capacity, and financial risk tolerance as dependent variables. Age, education, and income are measured on ordinal scales. Gender, marital status, and ethnicity are measured on a nominal scale. Risk attitude was measured by a 5-Likert scale with 11 indicators adapted from Metzger and Fehr (2017) and Lampenius and Zickar (2005). Risk capacity and risk tolerance were measured by 5 item Risk Tolerance Scale developed by Grable and Lytton (1999). Risk capacity using 10 indicators adapted from Injodey and Alex (2011) and Cooper et al. (2014). 
Risk tolerance using 9 Indicators, and 1 indicator as unity input for DEA adapted from Cooper et al. (2014). Data was collected through a structured questionnaire. The sample for the study consists of 438 Indonesian investors who were active in online stocks communities.

This study uses two research models. The first model will be analyzed using Structural Equation Modeling with Partial Least Square (i.e, PLS-SEM) estimation method to identify the associations between sociodemographic factors, multidimensional risk, and investor risk tolerance. The second model will be analyzed using Data Envelopment Analysis to assess the financial risk tolerance score of Investors based on their risk characteristics.

\section{Result and Discussion}

\section{Descriptive Statistic}

A descriptive statistic is used to describe the conditions and characteristics of the respondents' answers for each constructor variable in this study. Characteristics of respondents such as age, gender, education level, marital status, income, and ethnicity were also used as independent variables namely sociodemographic variables. Descriptive statistic respondents are presented in Table 1.

Tabel 1. Descriptive Statistic of Sociodemographic Variables.

\begin{tabular}{|c|c|c|c|}
\hline Variable & & Frequency & $\%$ \\
\hline \multirow{4}{*}{ Age } & Age $<24$ & 34 & 7.8 \\
\hline & Age $24-39$ & 213 & 48.6 \\
\hline & Age $40-59$ & 178 & 40.6 \\
\hline & Age $>60$ & 13 & 3.0 \\
\hline \multirow[t]{2}{*}{ Gender } & Male & 271 & 61.9 \\
\hline & Female & 167 & 38.1 \\
\hline \multirow[t]{4}{*}{ Education } & High School/ Equivalent & 58 & 13.2 \\
\hline & Diploma/ Equivalent & 52 & 11.9 \\
\hline & Bachelor Degree & 257 & 58.7 \\
\hline & $\geq$ Master Degree & 71 & 16.2 \\
\hline \multirow[t]{3}{*}{ Marital Status } & Single & 144 & 32.9 \\
\hline & Married & 278 & 63.5 \\
\hline & Divorced/ Widowed & 16 & 3.7 \\
\hline \multirow[t]{5}{*}{ Income } & $<\mathrm{Rp} \mathrm{5.000.000}$ & 67 & 15.3 \\
\hline & Rp 5.000.000 - Rp 10.000.000 & 110 & 25.1 \\
\hline & Rp 10.000.000 - Rp 20.000.000 & 118 & 26.9 \\
\hline & Rp 20.000.000 - Rp 50.000.000 & 121 & 27.6 \\
\hline & $>\mathrm{Rp} 50.000 .000$ & 22 & 5.0 \\
\hline \multirow[t]{6}{*}{ Ethnic } & Javanese & 156 & 35.6 \\
\hline & Batak & 30 & 6.8 \\
\hline & Malay & 84 & 19.2 \\
\hline & Other Indonesian origin & 99 & 22.6 \\
\hline & Non origin/ descent ethnic & 18 & 4.1 \\
\hline & Mixed ethnicity & 51 & 11.6 \\
\hline
\end{tabular}

Respondent in this study are dominated by the age of 24-39 years (48.6\%). More than half respondent are male (61.9\%) and the rest are female (38.1\%). 58.7\% Respondent had 
bachelor degree. The majority of respondent are married (63.5\%) and their most income levels are Rp20.000.000-Rp.50.000.000 (27.6\%). Most of them are Javanese (35.6\%).

Descriptive statistic will also analyze respondent statement about risk attitude, risk capacity and risk tolerance. The results are shown in Table 2. The total mean of these three variables will categorize as follow 1.00- 1.80 (very low); 1.81- 2.60 (low); 2.61- 3.40 (moderate); 3.414.20 (high); and 4.21- 5.00 (very high).

Table 2. Descriptive Statistic of Risk Attitude, Risk Capacity and Risk Tolerance Variables.

\begin{tabular}{|c|c|c|c|c|c|c|}
\hline \multicolumn{2}{|c|}{ Variables } & $\begin{array}{l}\text { Total } \\
\text { Score }\end{array}$ & $\begin{array}{l}\text { Standard } \\
\text { Deviation }\end{array}$ & Mean & $\begin{array}{l}\text { Total } \\
\text { Mean }\end{array}$ & Category \\
\hline \multirow{11}{*}{$\begin{array}{c}\text { Risk } \\
\text { Attitude }\end{array}$} & RA1 & 1570 & 1,037 & 3,58 & \multirow{11}{*}{3.53} & \multirow{11}{*}{ High } \\
\hline & RA2 & 1590 & 0,999 & 3,63 & & \\
\hline & RA3 & 1510 & 0,983 & 3,45 & & \\
\hline & RA4 & 1577 & 0,946 & 3,6 & & \\
\hline & RA5 & 1568 & 0,938 & 3,58 & & \\
\hline & RA6 & 1538 & 0,987 & 3,51 & & \\
\hline & RA7 & 1666 & 0,876 & 3,8 & & \\
\hline & RA8 & 1511 & 0,962 & 3,45 & & \\
\hline & RA9 & 1487 & 1,073 & 3,39 & & \\
\hline & $\overline{R A 10}$ & 1447 & 1,11 & 3,3 & & \\
\hline & $\overline{R A 11}$ & 1554 & 1,066 & 3,55 & & \\
\hline \multirow{10}{*}{$\begin{array}{c}\text { Risk } \\
\text { Capacity }\end{array}$} & $\mathrm{RC} 1$ & 1326 & 1,054 & 1,054 & \multirow{10}{*}{3.35} & \multirow{10}{*}{ Moderate } \\
\hline & $\mathrm{RC} 2$ & 1440 & 0,869 & 0,869 & & \\
\hline & RC3 & 1614 & 0,769 & 0,769 & & \\
\hline & $\mathrm{RC4}$ & 1517 & 0,796 & 0,796 & & \\
\hline & RC5 & 1572 & 1,134 & 1,134 & & \\
\hline & RC6 & 1623 & 0,736 & 0,736 & & \\
\hline & RC7 & 1601 & 0,972 & 0,972 & & \\
\hline & RC8 & 1444 & 1,204 & 1,204 & & \\
\hline & RC9 & 1312 & 0,932 & 0,932 & & \\
\hline & $\overline{\mathrm{RC} 10}$ & 1222 & 1,263 & 1,263 & & \\
\hline \multirow{9}{*}{$\begin{array}{c}\text { Risk } \\
\text { Tolerance }\end{array}$} & RT1 & 1259 & 0,994 & 2,87 & \multirow{9}{*}{3.06} & \multirow{9}{*}{ Moderate } \\
\hline & RT2 & 1487 & 0,88 & 3,39 & & \\
\hline & RT3 & 1446 & 1,172 & 3,3 & & \\
\hline & RT4 & 1378 & 0,854 & 3,15 & & \\
\hline & RT5 & 1419 & 0,91 & 3,24 & & \\
\hline & RT6 & 1427 & 1,028 & 3,26 & & \\
\hline & RT7 & 1372 & 1,029 & 3,13 & & \\
\hline & RT8 & 1216 & 1,236 & 2,78 & & \\
\hline & RT9 & 1065 & 1,185 & 2,43 & & \\
\hline
\end{tabular}

From the Table 2, it is inferred that total mean of risk attitude is 3.53 which categorize as high, thus, respondents in this study have high risk attitude. Risk capacity has total mean of 3.35 which categorize as moderate, then we can conclude that respondents have moderate risk capacity. The descriptive statistic also show that total mean of risk tolerance is 3.06, categorize as moderate, which means respondents has moderate risk tolerance. 


\section{Structural Equation Modelling (SEM) Result}

Model-1 has two different construct, reflective and normative, which are not possible to run in CB-SEM because an unidentified model will occur, hence, we choose Partial Least Square SEM (PLS-SEM) as the most appropriate approach suggest by many researcher. The developed conceptual model was drawn in smart PLS software.

In PLS analysis, we have to assess the measurement model (outer model) and continue with the structural model (inner model). The measurement model analysis was conducted to reflective model through convergent validity, discriminant validity, and construct reliability test. In examining the convergent validity, the average variance extracted (AVE) and item loadings are assessed (Hair et al., 2013). A loading value of 0.5 is regarded as acceptable, and a loading value less than 0.5 should be dropped (Hair et al., 2010). AVE value greater or equal to 0.50 is acceptable (Hair et al., 2013). Discriminant validity was evaluated by assessing the cross-loadings among constructs. To achieve discriminant validity, Chin (1998) proposed that each indicator loading should be greater than all of its cross-loadings. Construct's reliability measures by Cronbach alpha and composite reliability. The Cronbach's Alpha value is 0.7 or higher and the composite reliability score upper than 0.7 is a good indicator of construct reliability (Henseler and Sarstedt, 2013)

Based on the above criteria, the measurement model is evaluated by an iterative process to discard the weak manifest variables from the developed model. Thus, the result of the iteration requires two indicators to be eliminated. As for the result of the final measurement model shown in Table 3. 
90 | International Journal of Scientific and Management Research 4(4) 79-105

Table 3. Result of Measurement Model Evaluation.

\begin{tabular}{|c|c|c|c|c|c|c|c|c|}
\hline $\begin{array}{l}\text { Variables } \\
\text { (Reflective) }\end{array}$ & Indicators & $\begin{array}{l}\text { Loading } \\
(>0.5)\end{array}$ & \multicolumn{3}{|c|}{$\begin{array}{c}\text { Cross Loading } \\
\text { (Greater on its construct) }\end{array}$} & $\begin{array}{c}\text { Cronbach's } \\
\text { Alpha } \\
(>0.7)\end{array}$ & $\begin{array}{c}\text { Composite } \\
\text { Reliability } \\
(0.7)\end{array}$ & $\begin{array}{l}\text { AVE } \\
(>0.5)\end{array}$ \\
\hline \multirow{11}{*}{$\begin{array}{l}\text { Risk } \\
\text { Attitude }\end{array}$} & RA1 & 0,630 & 0.630 & 0.377 & 0.518 & \multirow{11}{*}{0,924} & \multirow{11}{*}{0,936} & \multirow{11}{*}{0,571} \\
\hline & RA10 & 0,710 & 0.710 & 0.551 & 0.644 & & & \\
\hline & RA11 & 0,799 & 0.799 & 0.409 & 0.612 & & & \\
\hline & RA2 & 0,771 & 0.771 & 0.396 & 0.577 & & & \\
\hline & RA3 & 0,835 & 0.835 & 0.522 & 0.696 & & & \\
\hline & RA4 & 0,686 & 0.686 & 0.443 & 0.502 & & & \\
\hline & RA5 & 0,781 & 0.781 & 0.482 & 0.598 & & & \\
\hline & RA6 & 0,793 & $\begin{array}{l}0.793 \\
\end{array}$ & 0.445 & 0.578 & & & \\
\hline & RA7 & 0,668 & 0.668 & 0.247 & 0.475 & & & \\
\hline & RA8 & 0,806 & 0.806 & 0.442 & 0.661 & & & \\
\hline & RA9 & 0,799 & 0.799 & 0.484 & 0.728 & & & \\
\hline \multirow{7}{*}{$\begin{array}{c}\text { Risk } \\
\text { Capacity }\end{array}$} & $\overline{\mathrm{RC} 1}$ & 0,600 & 0.459 & 0.600 & 0.534 & \multirow{7}{*}{0,838} & \multirow{7}{*}{0,879} & \multirow{7}{*}{0,511} \\
\hline & $\mathrm{RC} 3$ & 0,583 & 0.357 & 0.583 & 0.343 & & & \\
\hline & $\mathrm{RC} 4$ & 0,772 & 0.453 & 0.772 & 0.522 & & & \\
\hline & RC5 & 0,743 & 0.349 & 0.743 & 0.429 & & & \\
\hline & $\mathrm{RC7}$ & 0,751 & 0.501 & 0.751 & 0.496 & & & \\
\hline & $\overline{\mathrm{RC} 8}$ & 0,778 & 0.452 & 0.778 & 0.548 & & & \\
\hline & RC9 & 0,750 & 0.364 & 0.750 & 0.450 & & & \\
\hline \multirow{9}{*}{$\begin{array}{c}\text { Risk } \\
\text { Tolerance }\end{array}$} & $\overline{\mathrm{RT} 1}$ & 0,654 & 0.491 & 0.504 & 0.654 & \multirow{9}{*}{0,914} & \multirow{9}{*}{0,93} & \multirow{9}{*}{0,597} \\
\hline & $\overline{R T 2}$ & 0,832 & 0.664 & 0.551 & 0.832 & & & \\
\hline & RT3 & 0,745 & 0.621 & 0.420 & 0.745 & & & \\
\hline & $\begin{array}{l}\text { RT4 } \\
\end{array}$ & 0,729 & 0.631 & 0.622 & 0.729 & & & \\
\hline & $\overline{R T 5}$ & 0,713 & 0.593 & 0.482 & 0.713 & & & \\
\hline & RT6 & 0,860 & 0.699 & 0.496 & 0.860 & & & \\
\hline & RT7 & 0,866 & 0.708 & 0.588 & 0.866 & & & \\
\hline & $\begin{array}{l}\text { RT8 } \\
\end{array}$ & 0,804 & 0.619 & 0.510 & 0.804 & & & \\
\hline & RT9 & 0,720 & 0.526 & 0.461 & 0.720 & & & \\
\hline
\end{tabular}

Table 3 shows that all indicators in this measurement model meet the minimum requirement of the convergent validity such as loading value above 0.05 and also the AVE value above 0.05. All indicators also have the cross-loadings value on their construct that is higher than other constructs, hence, it confirms that each latent variable was discriminant to each other. Furthermore, the reliability test shows that all latent variables have Cronbach's Alpha value higher than 0.7 and the composite reliability score higher than 0.7 , hence, the model has good reliability.

Collinearity analysis was conducted to assess the validity and reliability of the measurement instrument for the formative constructs (i.e., sociodemographic factors). Collinearity analysis asses with Variance Inflation Factor (VIF). Table 4 shows that the VIF values for all indicators is not exceeding 10. If the VIF value is below 10 then there is a problem with multicollinearity (Hair et al., 2010). 
Tabel 4. Result of Multicollinearity Test

\begin{tabular}{|cc|}
\hline $\begin{array}{c}\text { Variables } \\
\text { (Formative) }\end{array}$ & VIF \\
Age & 1,000 \\
\hline Gender & 1,000 \\
Education & 1,000 \\
Marital Status & 1,000 \\
Income & 1,000 \\
Ethnic & 1,000 \\
\hline
\end{tabular}

After having a valid and reliable measurement model, we need to evaluate the structural model. The evaluation is conducted by asses $\mathrm{R} 2$ and testing the hypothesis. The primary criterion for structural model assessment is the coefficient of determination (R2), which represents the amount of variance in the construct that is explained by the exogenous variable in its endogenous counterpart (Chin, 1998). R2 values of 0.67, 0.33, and 0.19 can be described as respectively substantial, moderate, and weak (Chin, 1998). The R2 for each dependent construct is shown in Table 5.

Table 5. R-Square

\begin{tabular}{|l|r|r|c|}
\hline Endogenous Variable & R Square & R Square Adjusted & $\begin{array}{c}\text { Criteria } \\
\text { (Chin, 1998) }\end{array}$ \\
\hline Risk Attitude & 0.079 & 0.075 & Weak \\
\hline Risk Capacity & 0.397 & 0.394 & Moderate \\
\hline Risk Tolerance & 0.712 & 0.706 & Substantial \\
\hline
\end{tabular}

As can be seen in Table 5, the R2 values (0.075) of risk attitude can be considered as weak, this also means that predictors of exogenous variables (age and gender) explain $7.5 \%$ of the endogenous variable of risk attitude. R2 values (0.394) of risk capacity can be considered as moderate, this means the predictors of exogenous variables (age and income) explain $39.4 \%$ of the endogenous variable of risk capacity.

$\mathrm{R} 2$ values (0.706) of risk tolerance can be considered as substantial, this means the predictors of exogenous variables (sociodemographic factors, risk attitude, and risk capacity) explain $70.6 \%$ of the endogenous variable of risk tolerance.

In assessing the PLS path modeling have to employ the bootstrapping technique for testing the significance of all the path coefficients because in PLS analysis, bootstrapping is the only mechanism for examining the significance of path coefficients (Chin, 2010). Structural Model (Bootstrapping) show in Figure 3. 


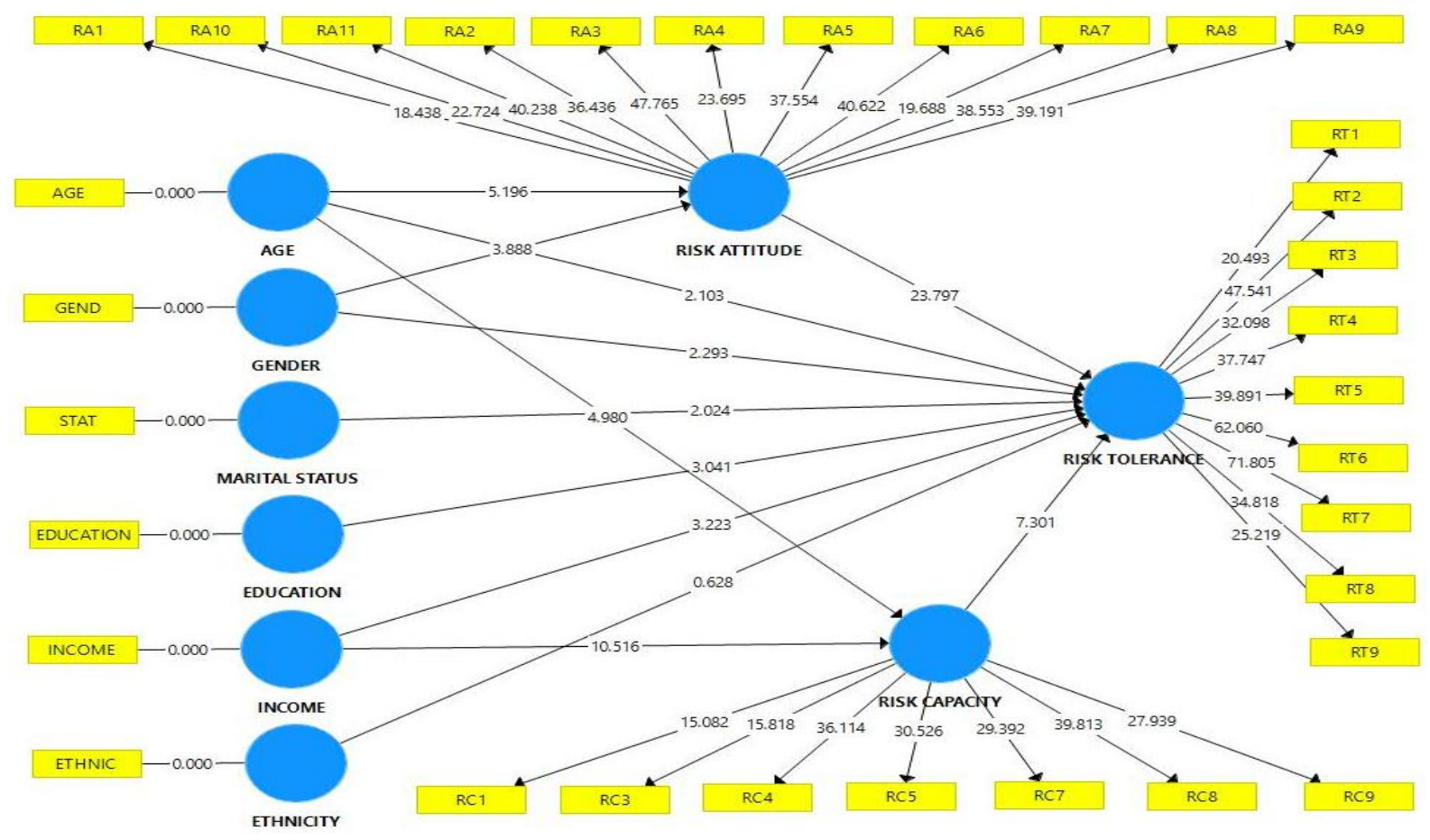

Figure 3. Structural Model (Bootstrapping)

Structural model in Figure 3. Show the path coefficients estimate using t-statistics. To be statistically significant t-value should be more than 1.96 for a two-tailed test with a $5 \%$ significance level and $\mathrm{p}$ values are not greater than 0.05 (Hair et al., 2010). Path coefficient analysis was employed to test the hypothesis. The mediated effect was analyzed through a path coefficient stated in a specific indirect effect table. All PLS-SEM results are shown in Table 6.

Table 6. PLS-SEM Result- Path Coefficient Analysis.

\begin{tabular}{|c|l|r|r|r|r|}
\hline Hypothesis & \multicolumn{1}{|c|}{ Relation } & \multicolumn{1}{c|}{ Coeff. } & \multicolumn{1}{c|}{ T Stat. } & \multicolumn{1}{l|}{ Prob. } & Sig. \\
\hline H1a & Age $\rightarrow$ Risk Tolerance & 0,064 & 2,103 & 0,036 & Significant \\
\hline H1b & Gender $\rightarrow$ Risk Tolerance & $-0,057$ & 2,293 & 0,022 & Significant \\
\hline H1c & Marital Status $\rightarrow$ Risk Tolerance & $-0,056$ & 2,024 & 0,043 & Significant \\
\hline H1d & Education $\rightarrow$ Risk Tolerance & $-0,091$ & 3,041 & 0,002 & Significant \\
\hline H1e & Income $\rightarrow$ Risk Tolerance & 0,116 & 3,223 & 0,001 & Significant \\
\hline H1f & Ethnic $\rightarrow$ Risk Tolerance & 0,015 & 0,628 & 0,530 & $\begin{array}{r}\text { Not } \\
\text { significant }\end{array}$ \\
\hline H2a & Risk Attitude $\rightarrow$ Risk Tolerance & 0,604 & 23,797 & 0,000 & Significant \\
\hline H2b & Risk Capacity $\rightarrow$ Risk Tolerance & 0,260 & 7,301 & 0,000 & Significant \\
\hline H3a & Age $\rightarrow$ Risk Attitude & 0,222 & 5,196 & 0,000 & Significant \\
\hline H3b & Gender $\rightarrow$ Risk Attitude & $-0,172$ & 3,888 & 0,000 & Significant \\
\hline H3c & Age $\rightarrow$ Risk Capacity & 0,245 & 4,980 & 0,000 & Significant \\
\hline H3d & Income $\rightarrow$ Risk Capacity & 0,469 & 10,516 & 0,000 & Significant \\
\hline H4a & Age $\rightarrow$ Risk Attitude $\rightarrow$ Risk Tolerance & 0,134 & 5,245 & 0,000 & Significant \\
\hline H4b & Gender $\rightarrow$ Risk Attitude $\rightarrow$ Risk Tolerance & $-0,104$ & 3,817 & 0,000 & Significant \\
\hline H4c & Age $\rightarrow$ Risk Capacity $\rightarrow$ Risk Tolerance & 0,064 & 3,996 & 0,000 & Significant \\
\hline H4d & Income $\rightarrow$ Risk Capacity $\rightarrow$ Risk Tolerance & 0,122 & 5,917 & 0,000 & Significant \\
\hline
\end{tabular}




\section{3 | International Journal of Scientific and Management Research 4(4) 79-105}

Based on Table 6, It is indicated that sociodemographic factor, namely age, gender, marital status, education, and income has a significant effect on risk tolerance, while ethnic has not. Age has significant effect on risk tolerance ( $\mathrm{t}$ stat $=2.103>1.96$ and $\mathrm{p}$ values $=0.036<0.05)$. Therefore, the proposed alternative hypothesis (H1a) is accepted. The coefficient value 0.064 shows that the relations between two variables are positive. As the age increased, risk tolerance increased. This result supports the previous study from Grable (2000) and Wang and Hanna (1998) which found a positive relationship between age and risk tolerance. Younger individuals tend to have limited financial resources to bear short-term losses so that risk tolerance is lower. Older investors have spent a long time accumulating wealth to improve their financial capabilities so that they become more economically stable and more able to bear more risk. They are usually also more experienced and confident when making risky investment decisions.

Gender has significant effect on risk tolerance ( $\mathrm{t}$ stat $=2.293>1.96$ and $\mathrm{p}$ values $=0.022<$ 0.05). Therefore, the proposed alternative hypothesis ( $\mathrm{H} 1 \mathrm{~b})$ is accepted. The coefficient value $-0,057$ shows that there is a difference in gender on risk tolerance. In this study, the male is measured with 1 , and female with 2 , thus, men are more risk tolerance than women. This result supports the previous study from Bajtelsmit and Bernasek, (1996), Pålsson, (1996), Roszkowski and Grable, (2005). Men tend to be rasher in making decisions, so they are more willing to take risks without first considering their impact on the future. Whereas men usually prefer challenges, they are happy with investments that are quite risky and challenging.

Marital status has significant effect on risk tolerance $(\mathrm{t}$ stat $=2.024>1.96$ and $\mathrm{p}$ values $=$ $0,043<0.05)$. Therefore, the proposed alternative hypothesis (H1c) is accepted. The coefficient value $-0,056$ shows that there is a difference in marital status on risk tolerance. In this study, Single is measured with 1 , married with 2 , and divorced/widowed with 3 , thus single is more risk tolerance than married or widowed/divorce. This result supports the previous study from Roszkowski, Snelbecker, and Leimberg (1993), Sung and Hanna (1996), and Grable and Joo (2000) which also found that single individuals who are not married are more risk-tolerant than married individuals. They, who are single, have a tendency to take greater risks because they don't have much responsibility if they experienced losses than married couples.

Education has significant effect on risk tolerance $(\mathrm{t}$ stat $=3.041>1.96$ and $\mathrm{p}$ values $=0,002<$ 0.05). Therefore, the proposed alternative hypothesis (H1d) is accepted. The coefficient value of -0.091 shows that the relations between the two variables are negative. High-educated people are more risk tolerance. In this study, the education level of respondents was only measured with their formal education, hence, it does not guarantee that their knowledge of risk is better than low educated people. In this study, we can conclude that Indonesian investor who has high education might be less risk tolerance because they are not well financial literate.

Income has significant effect on risk tolerance ( $\mathrm{t}$ stat $=3,223>1.96$ and $\mathrm{p}$ values $=0,001<$ $0.05)$. Therefore, the proposed alternative hypothesis (H1e) is accepted. The coefficient value 0,116 shows that the relations between two variables are positive. This result supports the previous study from Riley and Chow, (1992), Grable and Lytton (1999). An investor who earned high income can easily bear losses due to risky investments and they can financially recover faster. An investor who earned less income doesn't have many resources in making risky investment choices, hence, their risk tolerance is lower. 


\section{4 | International Journal of Scientific and Management Research 4(4) 79-105}

Ethnic doesn't has significant effect on risk tolerance ( $\mathrm{t}$ stat $=0,628<1.96$ and $\mathrm{p}$ values $=0$, $0530>0.05)$. Therefore, the proposed alternative hypothesis (H1f) is rejected. We believe that ethnicity can define someone's identity. But there has been a shift in cultural identity lately especially for those who live in big cities. Javanese people who are known to be gentle and prudent may become rash because of social influences, hence, we cannot identify someone's risk tolerance based on their ethnicity.

Table 6 also shows that multidimensional risk has an effect on risk tolerance. Risk attitude has positive significant effect on risk tolerance (coef. $=0.604$, t stat $=23,797>1.96$ and $p$ values $=0,000<0.05$ ). Risk capacity has positive significant effect on risk tolerance (coef. $=$ 0.260 , $\mathrm{t}$ stat $=7,301>1.96$ and $\mathrm{p}$ values $=0,000<0.05$ ). Therefore the proposed alternative hypotheses ( $\mathrm{H} 2 \mathrm{a}$ and $\mathrm{H} 2 \mathrm{~b})$ are accepted. These two results support the study of Cordell (2001, 2002). Investor tends to behave risk-averse when they are faced with the choice to invest low returns-low risks or high returns-high risks, they prefer the first choice. But along with his ability to adapt to risks, the risk tolerance may increase so that for them the low risk becomes too low, and they can adjust to make investments that have a slightly higher risk. Therefore, risk attitude increase as risk tolerance increase. While risk capacity is the investor "ability" of risk-taking and risk tolerance is the investor "desire" of risk-taking, hence, these two forms should be in harmony. Risk capacity increases as risk tolerance increases.

Another Finding in Table 6 indicated that sociodemographic factors used in this study has a significant effect on multidimensional risk. Age has positive significant effect on risk attitude (coeff. $=0.222, \mathrm{t}$ stat $=5,196>1.96$ and $\mathrm{p}$ values $=0.000<0.05)$. Gender has significant effect on risk attitude (coeff. $=-0.172, \mathrm{t}$ stat $=3,888>1.96$ and $\mathrm{p}$ values $=0.000<0.05$ ). Therefore, the proposed alternative hypotheses $(\mathrm{H} 3 \mathrm{a}$ and $\mathrm{H} 3 \mathrm{~b}$ ) are accepted. Respondents in this study tend to have less risk attitude for those who are young, and more risk attitude for those who are elderly, as Hallahan et al. (2004) state that risk attitudes decrease as age increases. Riley and Chow (1992) stated that people aged around 55 years and over have more risky behavior. Female has less risk attitude then male as Barber and Odean (2001) state that risk attitudes are lower for women than men. Women have a longer life expectancy, show greater responsibility for their families, and have lower lifetime income potential, and so on (Kannadhasan (2015). Age has positive significant effect on risk capacity (coeff. = 0.245 , $\mathrm{t}$ stat $=4,980>1.96$ and $\mathrm{p}$ values $=0.000<0.05$ ). Income has positive significant effect on risk capacity (coeff. $=0.469, \mathrm{t}$ stat $=10,516>1.96$ and $\mathrm{p}$ values $=0.000<0.05$ ). Therefore, the proposed alternative hypotheses ( $\mathrm{H} 3 \mathrm{c}$ and $\mathrm{H} 3 \mathrm{~d}$ ) are accepted. In this study younger people have a high-risk capacity objectively, it is because of the traditionally low ratio of financial assets to total wealth (Zanella, 2015) and people with higher income have a greater capacity to incur risk (O’Neill, 1996).

Table 6 show results of hypothesis testing $(\mathrm{H} 4 \mathrm{a}$ and $\mathrm{H} 4 \mathrm{~b})$ where risk attitude mediates age (coeff. $=0.134, \mathrm{t}$ stat $=5,245>1.96$ and $\mathrm{p}$ values $=0.000<0.05)$ and gender $($ coeff. $=-0.104$, $\mathrm{t}$ stat $=3,817>1.96$ and $\mathrm{p}$ values $=0.000<0.05$ ) to risk tolerance. As age increased, the risk attitude increase, hence risk tolerance will also increase, and the risk attitude of men is higher than women, hence, their risk tolerance will also be higher than women. Furthermore, Table 6 also show result of hypothesis testing $(\mathrm{H} 4 \mathrm{c}$ and $\mathrm{H} 4 \mathrm{~d})$ where risk capacity mediates age (coeff $=0.064$, t stat $=3,996>1.96$ and $\mathrm{p}$ values $=0.000<0.05)$ and income $($ coeff.$=0.122$, $\mathrm{t}$ stat $=$ $5,917>1.96$ and $\mathrm{p}$ values $=0.000<0.05$ ) to risk tolerance. As age and income increased, the risk capacity increase, hence risk tolerance will also increase. Therefore, these four mediating hypotheses (H4a, H4b, H4c, and $\mathrm{H} 4 \mathrm{~d}$ ) are accepted. This finding provides a new contribution to researches about risk tolerance. 


\section{Data Envelopment Analysis Result}

Data collected from the questionnaire were analyzed with the DEA-BCC: SBM-output oriented model using MaxDEA 8 Basic software. DEA will generate an efficient DMU with a score of 1 and inefficiencies DMU with a score below 1. This indicates that investors with DEA scores $=1$ show high-risk tolerance, and investors with DEA scores $<1$ are considered to be less risky (less risk tolerance). Summary of DEA shown in Table 7.

\section{Tabel 7. Summary of Result of DEA-SBM Model.}

\begin{tabular}{|l|l|}
\hline \multicolumn{1}{|c|}{ Property } & \multicolumn{1}{c|}{ Value } \\
\hline Number of DMUs & 438 \\
\hline Number of Efficient DMU & 123 \\
\hline Number of Inputs & 1 \\
\hline Number of Outputs & 30 \\
\hline Maximum Score & 1 \\
\hline Minimun Score & 0.388 \\
\hline Average DEA Score & 0.797 \\
\hline Distance & SBM, Slacks-based Measure (Tone 2001) \\
\hline Orientation & Output-oriented \\
\hline Returns to Scale & Variable \\
\hline
\end{tabular}

Table 7 shows that the average DEA score of 438 DMU is 0.797 , with 123 efficient DMUs (28.08\%) and the rest of 315 DMUs (71.92\%) are innefficient. From the acquisition of the DEA score the frontier will be formed as shown in figure 4.

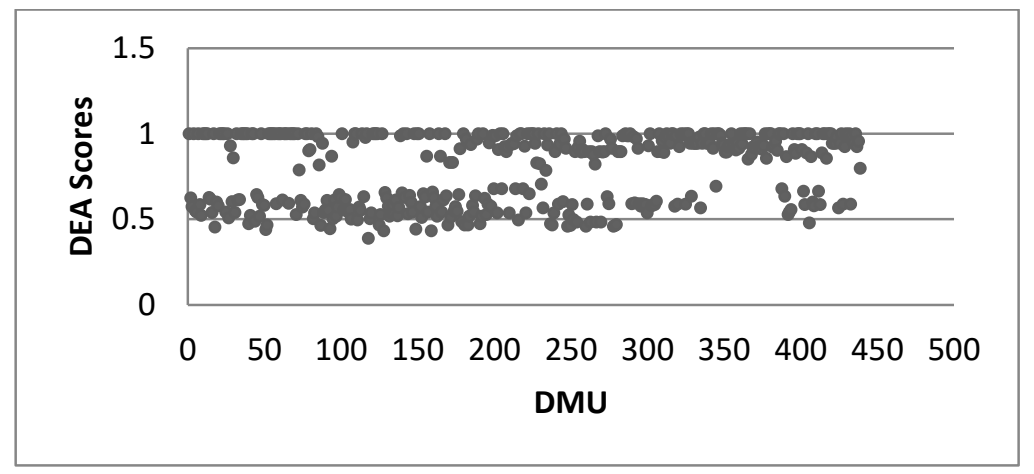

Figure 4. Frontier of DEA Scores of DMU

Based on Figure 4, it can be seen that Investors (DMUs) with high-risk tolerance will form a frontier at a value of 1 . While investors with less risk tolerance or risk-averse will be far from the frontier.

As discussed previously, the results DEA scores were carried out to investigate whether risk tolerance is different, on average, between the available categories of sociodemographic variables such as age, gender, marital status, education, income, and ethnicity. Therefore, the average DEA score will be used as the response variable for statistically describe investor risk profile as shown in Table 7. 
Table 8. Risk Profile using Average DEA Scores

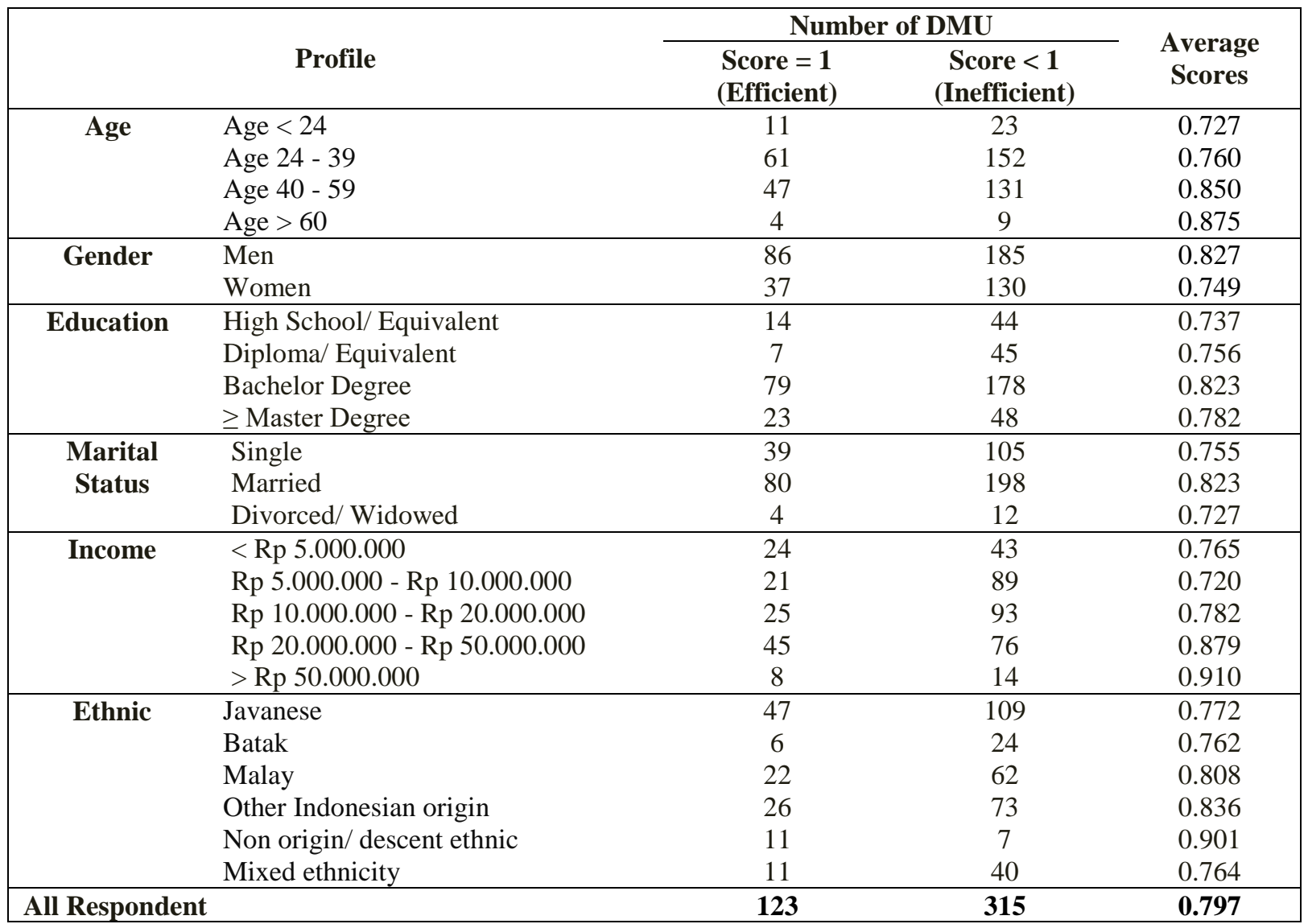

Based on the table above, it is generally known that most of respondent are inefficient DMU and have DEA Scores < 1, hence, most of them are less risk tolerance. This evidence provide that few of Indonesian investor tend to have high financial risk tolerance, thus, hypothesis (H5) is rejected. Data Envelopment Analysis (DEA) shows that most of Indonesian investor are less risk tolerance. To specifically determine the value of risk tolerance based on the range of DEA scores, we made risk-profile line as follow:

\begin{tabular}{|lrrr|}
\hline \multicolumn{2}{l}{ Risk Averse } & Risk Netral & Risk Seeker \\
\cline { 2 - 4 } & Low Risk Averse & $\mathbf{0 . 5}$ & Low Risk Seeker $\mathbf{1}$ \\
\hline
\end{tabular}

The average DEA score for all investors shows a value of 0.797 indicates that indonesian investors are low risk seeker, and most of them have less risk tolerance.

Risk profiling assesment with DEA (shown in Table 8) also support some hyphotesis in Model 1. DEA scores shows that older investors are more risk-tolerant than younger investors. This support the findings in hypothesis H1a that age has positive significant effect on risk tolerance. Average risk tolerance for different ages using DEA shown in Figure 5. 


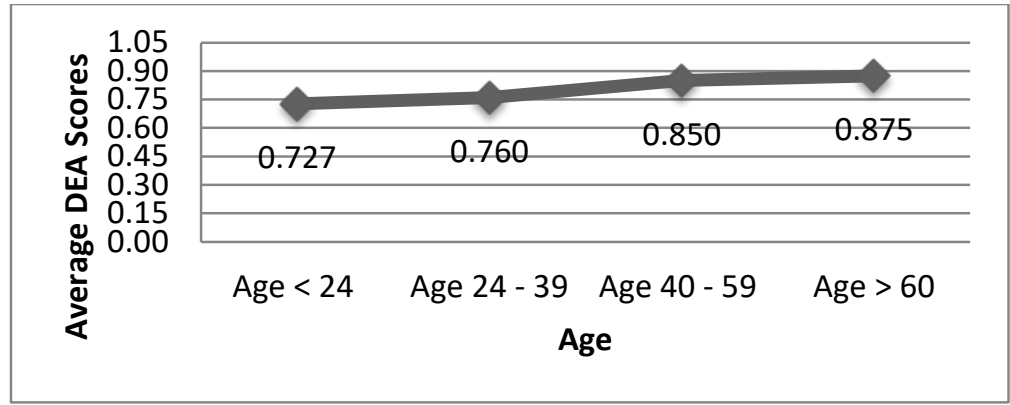

Figure 5. Average Risk Tolerance (DEA Scores) for Age

DEA scores also shows that male investors are more risk-tolerant than female investors. This support the findings in hypothesis (H1b) that gender has significant effect on risk tolerance. Average risk tolerance for gender using DEA shown in Figure 6.

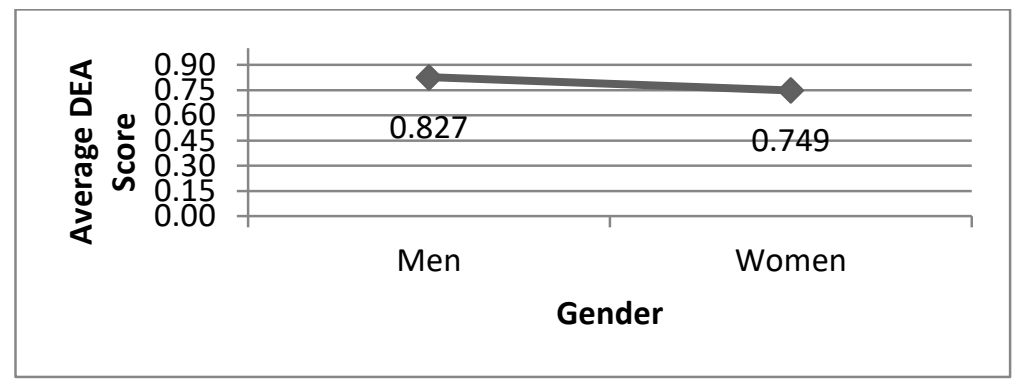

Figure 6. Average Risk Tolerance (DEA Scores) for Gender

There is an interesting finding in DEA Scores generated by education. Investor with a Bachelor Degree/ Equivalent have a higher risk tolerance than investors who have a level of education below it, but for investor with master degree or higher, their risk tolerance tends to decrease. Result of hypothesis H1c show that education has negative significant effect on financial risk tolerance. This statement is not entirely wrong, because DEA score show that somehow investor with much higher education has less risk tolerance than investor with education bellow it. Average risk tolerance for education using DEA shown in Figure 7.

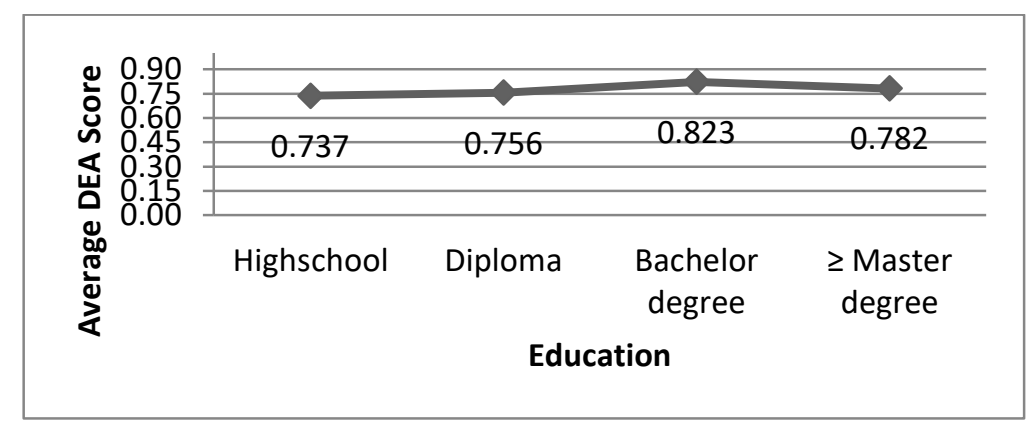

Figure 7. Average Risk Tolerance (DEA Scores) for Education

DEA scores show that married investor are more risk tolerance than unmarried investor (i.e., single, divorced/widowed). This support the findings in hypothesis (H1d) that marital status has significant effect on risk tolerance. Average risk tolerance for marital status using DEA shown in Figure 8. 


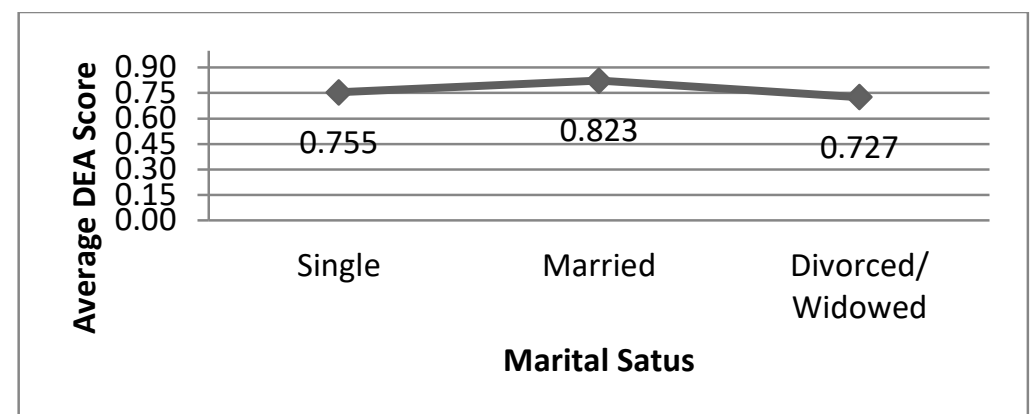

Figure 8. Average Risk Tolerance (DEA Scores) for Marital Status

DEA scores show that investors with high income are more risk tolerance than investors with low income. This support the findings in hypothesis (H1e) that income has positive significant effect on risk tolerance. Average risk tolerance for investor income level using DEA shown in Figure 9.

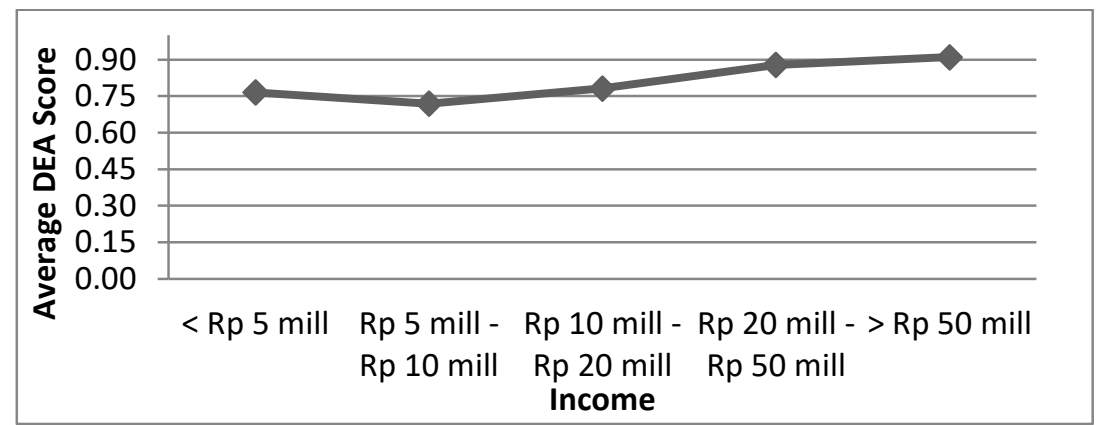

Figure 9. Average Risk Tolerance (DEA Scores) for Income Level

DEA result varied scores for different ethnic. Highest scores is obtained by non origin/descent ethnic (i.e., chinese, tionghoa, arabic, indian) in Indonesia. However, the varied scores form other ethnic indicated inconsistency result, so the there is no conclusion can be drawn. Result of hypothesis H1f show that ethnicity doesn't have significant effect on financial risk tolerance. Thus, these two result from DEA model and SEM model are almost similar, that ethnicity can not be considered in differentiate investor risk tolerance. Average risk tolerance for ethnicity using DEA shown in Figure 10.

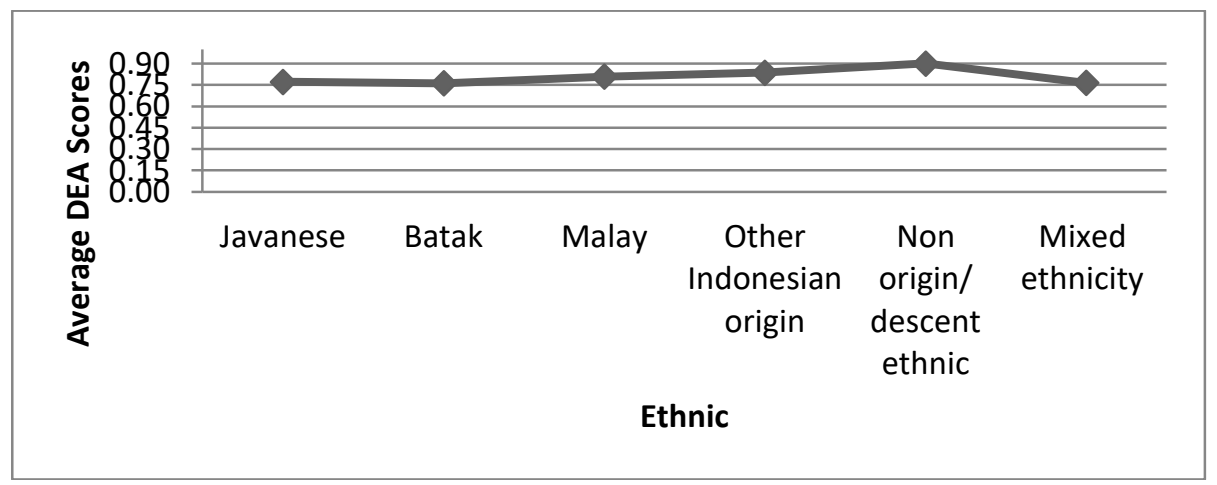

Figure 10. Average Risk Tolerance (DEA Scores) for Ethnicity

\section{Conclusion}

Our research aims to investigate the relationship between sociodemographic factors, multidimensional risk, and financial risk tolerance. This research result that 
sociodemographic factors such as age, gender, marital status, education, and income were found to have a significant effect on risk tolerance, while ethnicity is found to have a not significant effect on risk tolerance.

This research also considered a multidimensional risk as to the factor that affects financial risk tolerance and found a result that two dimensions of risk, namely: risk attitude and risk capacity have a positive significant effect on risk tolerance. This two-dimension of risk has also proven to be a potential mediator between sociodemographic factors and risk tolerance. Age and gender have a significant effect on risk attitude, while age and income have a significant effect on risk capacity.

Our approach using DEA as a risk tolerance assessment shows that DEA can effectively be applied for generating the risk profile of Indonesian investors, despite the alternative hypothesis is rejected and gives the result that most Indonesian investors tend to have less risk tolerance.

This research is expected to be used by investors and financial advisors in assessing risk tolerance to determine the best investment choices and best suits the characteristics of investors. Furthermore, the results of this study can also be used to develop a risk tolerance assessment by considering the multidimensional risk as an integral part of the instrument.

Finally, we can suggest for further research to consider other sociodemographic factors such as religion or employment status to get the whole picture of investor risk profiling. Considering other multidimensional of risks such as risk knowledge and risk propensity will be a good opportunity to opening up all sorts of research.

\section{References}

1) Anbar, A., Eker, M., 2010. An Empirical Investigation for Determining of The Relation Between Personal Financial Risk Tolerance and Demographic Characteristic. Ege Acad. Rev. 10, 503-522.

2) Ardehali, P.H., Paradi, J.C., Asmild, M., 2005. Assessing Financial Risk Tolerance of Portfolio Investors Using Data Envelopment Analysis. Int. J. Inf. Technol. Decis. Mak. 04, 491-519. https://doi.org/10.1142/s0219622005001660

3) Bajtelsmit, V.L., Bernasek, A., 1996. Why Do Women Invest Differently Than Men? Financ. Couns. Plan. 7.

4) Barber, B.M., Odean, T., 2001. Boys Will Be Boys: Gender, Overconfidence, And Common Stock Investment. Q. J. Econ. 116, 261-292.

5) Bosner, K., Lakehal-Ayat, M., 2008. A Comparison of Risk Tolerance and Risk Capacity among College Finance Students. Acad. Account. Financ. Stud. J. 12.

6) Brayman, S., 2012. Defining and Measuring Risk Capacity. Financ. Serv. Rev. 21, 131-148.

7) Campbell, J.Y., 2006. Household Finance. J. Finance LXI.

8) Chang, C.C., Devaney, S.A., Chiremba, S.T., 2004. Determinants of subjective and objective risk tolerance. J. Pers. Financ. 3, 53-67.

9) Charnes, A., Cooper, W.W., Rhodes, E., 1978. Measuring The Efficiency of Decision Making Units. Eur. J. Oper. Res. 2, 429-444.

10) Chin, W., 1998. The Partial Least Square Approach for Structural Equation Modeling. Cleveland. Ohio.

11) Cooper, W.W., Kingyens, A.T., Paradi, J.C., 2014. Two-stage financial risk tolerance assessment using data envelopment analysis. Eur. J. Oper. Res. 233, 273-280. https://doi.org/10.1016/j.ejor.2013.08.030 
12) Cordell, D.M., 2002. Risk tolerance in two dimensions. J. Financ. Plan.

13) Cordell, D.M., 2001. RiskPACK: How to Evaluate Risk Tolerance. J. Financ. Plan. $14,36-40$.

14) Dilworth-Anderson, P., Burton, L., Johnson, L., 1993. Reframing theories for understanding race, ethnicity, and families. In Ross, P., Doherty, W., LaRossa, R., Schu, W., \& Steinmetz, S., Sourcebook of Family theories and methods: A contextual approach. Plenum Press, New York.

15) Faff, R.W., Mulino, D., Chai, D., 2006. On the Linkage between Financial Risk Tolerance and Risk Aversion: Evidence from a Psychometrically-Validated Survey Versus an Online Lottery Choice Experiment. Ssrn. https://doi.org/10.2139/ssrn.946679

16) Grable, J., Joo, S., 2004. Environmental and biopsychosocial factors associated with financial risk tolerance. J. Financ. Couns. Plan. 15, 73-82.

17) Grable, J, Lytton, R., 1999. Financial risk tolerance revisited: the development of a risk assessment instrument. Financ. Serv. Rev.

18) Grable, John, Lytton, R.H., 1999. Financial risk tolerance revisited: The development of a risk assessment instrument. Financ. Serv. Rev. 8, 163-181.

19) Grable, J.E., 2016. Financial Risk Tolerance. Handb. Consum. Financ. Res. 1-424. https://doi.org/10.1007/978-0-387-75734-6

20) Grable, J.E., 2008. Risk Tolerance. Handb. Consum. Financ. Res. 175-175.

21) Grable, J.E., 2000. Financial Risk Tolerance And Additional Factors That Affect Risk Taking in Everyday Money Matters. J. Bus. Psychol. 14, 625-630.

22) Grable, J.E., Lytton, R.H., 2001. Assessing the concurrent validity of the SCF risk tolerance question. J. Financ. Couns. Plan. 12, 43-53.

23) Grable, J.E., Lytton, R.H., 1998. Investor risk tolerance: Testing the efficacy of demographics as differentiating and classifying factors. Financ. Couns. Plan. 9, 6173.

24) Gutter, M.S., 2000. Human Wealth and Financial Asset Ownership. Financ. Couns. Plan. 11, 9-19.

25) Hair, J.F., Ringle, C.M., Sarstedt, M., 2013. Partial least squares structural equation modeling: Rigorous applications, better results and higher acceptance. Long Range Plann. 46, 1-12.

26) Hair, J.F.J., Anderson, R.., Tatham, R.L., Black, W.C., 2010. Multivariate Data Analysis, 5th editio. ed. Upper Saddle River: Prentice Hall.

27) Hallahan, T.A., Faff, R.W., McKenzie, M.D., 2004. An empirical investigation of personal financial risk tolerance. Financ. Serv. Rev. 13, 57-78. https://doi.org/10.1038/nri2781

28) Henseler, J., Sarstedt, M., 2013. Goodness-of-fit Indices for Partial Least Squares Path Modeling. Comput. Stat. 28, 565-580.

29) Injodey, J., Alex, D., 2011. Risk Tolerance of Investors: Developing a Psychometric Tool. Res. J. Financ. Account. 2, 1-20.

30) Kannadhasan, M., 2015. Retail investors' financial risk tolerance and their risk-taking behaviour: The role of demographics as differentiating and classifying factors. IIMB Manag. Rev. 27, 175-184. https://doi.org/10.1016/j.iimb.2015.06.004

31) KSEI, 2019. KSEI 2019 Achievements: Implementing a New Historical Milestone for the Indonesian Capital Market. Press Release KSEI 1-4.

32) Lampenius, N., Zickar, M.J., 2005. Development and Validation of a Model and Measure of Financial Risk-Taking. J. Behav. Financ. 6, 129-143. https://doi.org/10.1207/s15427579jpfm0603

33) MacCrimmon, K.R., Wehrung, D.A., 1986. Taking risks: The management of 
uncertainty, New York : Free Press.

34) Metzger, B.A., Fehr, R.R., 2017. Measuring Financial Risk Attitude: How to Apply Both Regulatory and Scientific Criteria to Ensure Suitability. J. Behav. Financ. 19, 221-234. https://doi.org/10.1080/15427560.2017.1376331

35) O’Neill, B., 1996. Baby boomers at mid-life: financial planning for 2000 and beyond. J. Fam. Consum. Sci. 88, 3-8.

36) Ogden, D.T., Ogden, J.R., Schau, H.J., 2004. Exploring the impact of culture and acculturation on consumer purchase decisions: Toward a microcultural perspective. Acad. Mark. Sci. Rev. 8, 1-22.

37) Pålsson, A.M., 1996. Does the degree of relative risk aversion vary with household characteristics? J. Econ. Psychol. 17, 771-787. https://doi.org/10.1016/S01674870(96)00039-6

38) Praba, R.S., 2016. Financial Risk Tolerance and the influence of Socio-demographic Characteristics of Retail Investors. ISBR Manag. J. 1, 33-41.

39) Roszkowski, M., Davey, G., Grable, J., 2005. Insights from Psychology and Psychometrics on Measuring Risk Tolerance. J. Financ. Plan. 18, 66-77.

40) Roszkowski, M.J., Grable, J., 2005. Gender Stereotypes in Advisors' Clinical Judgments of Financial Risk Tolerance: Objects in the Mirror Are Closer than They Appear. J. Behav. Financ. 6, 181-191. https://doi.org/10.1207/s15427579jpfm0604

41) Roszkowski, M.J., Snelbecker, G.E., Leimberg, S.R., 1993. Risk-tolerance and risk aversion. tools Tech. Financ. Plan. 4, 213-225.

42) Subramaniam, V., Athiyaman, T., 2016. The Effect of Demographic Factors on Investor's Risk Tolerance. Int. J. Commer. Manag. Res. 2, 136-142.

43) Sung, J., Hanna, S., 1996. Factors Related to Risk Tolerance. Financ. Couns. Plan. 7.

44) Wang, H., Hanna, S.D., 1998. Does Risk Tolerance Decrease with Age? Financ. Couns. Plan. 8, 27-32. https://doi.org/10.2139/ssrn.95489

45) Weber, E.U., Blais, A., Betz, N.E., 2002. A domain-specific risk-attitude scale: measuring risk perceptions and risk behaviors. J. Behav. Decis. Mak. 15, 263-290. https://doi.org/10.1002/bdm.414

46) Zanella, N., 2015. Risk Capacity over the Life Cycle : The Role of Human Capital, High Priority Goals, and Discretionary Wealth. J. Wealth Manag. 27-36.

\section{Works Cited}

Irna Puji Lestari. (2021). Effect of Sociodemographic Factors and Multidimensional of Risk Toward Financial Risk Tolerance and Risk Tolerance Assessment Using Data Envelopment Analysis of Indonesian Investors. International Journal of Scientific and Management Research, 04(04), 79-105. doi:http://doi.org/10.37502/IJSMR.2021.4407 


\section{APPENDIX QUESTIONAIRE}

\section{A. Respondent Demographic}

Age:

$$
<24
$$

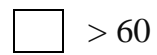

Gender :

Male $\square$ Female

Marital status:
$\square$ Single
Married
Divorced/ Widowed

Highest Level of Education (equivalent) Attained:
$\square$ Highschool
Diploma
$\square$ Bachelor Degree
$\square$ Master degre or higher

Monthly income from all source - before tax :
$<\operatorname{Rp5} .000 .000$
Rp5.000.000-Rp10.000.000
Rp 10.000.000 - Rp 20.000.000
Rp 20.000.000 - Rp 50.000.000
$\longrightarrow$ Rp50.000.000

Ethnicity
Javanese $\square$ Batak
Malay
Other Indonesian Origin
Non origin/ descent ethnic
Mixed ethnicity

\section{B. Risk Attitude}

\begin{tabular}{|c|c|c|c|c|c|}
\hline Statements & 1 & 2 & 3 & 4 & 5 \\
\hline $\begin{array}{l}\text { The uncertainty of whether the markets will rise or fall keeps me from } \\
\text { buying stocks }\end{array}$ & & & & & \\
\hline $\begin{array}{l}\text { Stock markets are unpredictable, which is why I would never invest in } \\
\text { stocks }\end{array}$ & & & & & \\
\hline In money matters, I tend to be willing to take risks & & & & & \\
\hline $\begin{array}{l}\text { I am willing to take financial risks in order to substantially increase my } \\
\text { assets }\end{array}$ & & & & & \\
\hline $\begin{array}{l}\text { I am aiming for capital growth in the long run, which is why I am } \\
\text { willing to take considerable financial risks }\end{array}$ & & & & & \\
\hline I like to seek thrills in having high returns on investments & & & & & \\
\hline I see risk as an opportunity to make money & & & & & \\
\hline I get a thrill out of investing & & & & & \\
\hline $\begin{array}{l}\text { When I invest money a high return on my investment, even though it } \\
\text { means accepting a high degree of risk, is the most important aspect }\end{array}$ & & & & & \\
\hline When I invest money a safe return is very important to me & & & & & \\
\hline $\begin{array}{l}\text { I prefer putting money into a bank account because then I know exactly } \\
\text { how much money I will have in the future }\end{array}$ & & & & & \\
\hline
\end{tabular}

Note:

1 = Very dissagree, 2 = Disagree, $3=$ Netral, 4 = Agree, $5=$ Very Agree 
C. Risk Capacity

1. Please estimate when you will need to withdraw $20 \%$ of your current portfolio value, such as a need for a house down payment or some other major financial need?

1. Less than 1 year

2. $1-3$ year

3. 3 - 5 year

4. $5-10$ years

5. More than 10 years

2. Please select your primary investment objective

1. Retirement

2. Education fundings for children

3. Wealth accumulation

4. Large purchase or down payment (for home, car, vacation, renovation)

5. Current income

3. Over the next 2-3 years, your income will be:

1. Unstable

2. Less stable compared to today

3. Stable as today

4. More stable than today

5. Very stable

4. Which of the following best describes your source of income?

1. Do not have a safe source of income

2. Have a secure source of income but only enough to meet daily needs

3. Have a secure source of income with a small surplus to save

4. Have a secure source of income with a lot of surplus to buy tertiary needs

5. Have a secure and excessive amount of income so that primary, secondary and tertiary needs are met, and can invest in large portions

5. Please mark the choice most appropriate regarding your assets you own

1. Have no assets at all

2. Have at least 1 property (e.g. house)

3. Have at least 1 property and vehicles (e.g. 1 house and 1 car)

4. Have more than 1 property and vehicles (e.g. 1 house, 1 villa and 2 cars)

5. Have more than 1 property, vehicles and other liquid assets (e.g. house, villa, car, stocks)

6. How many times is your domestic debt compared to your income?

1. More than 5 times the annual income

2. 3-5 times annual income

3. 1-2 times annual income

4. Less than 1 times the annual income

5. No debt at all

7. Please identify the sources of your income (include only those sources which provide at least up to $10 \%$ of your total income)

1. Wages or unfixed salary/ honorariums

2. Job/ self employment / business alone

3. Salary

4. Salary and business income

5. Salary, business income, and other investment income

8. Which of the following best describes your position with insurance?

1. I have no insurance coverage at all

2. I have only insurance provide by government

3. I have covered all the significant risks only (e.g. health or education insurance)

4. I have covered all the substantial risks and it is sufficient to give current level of income

5. I am very much under insured and including insurance for investment risk

9. Which of the following best describes you income position?

1. My annual income is less than my annual expenditure

2. My annual income is as much as my annual expenditure

3. My annual income is about 2-3 times my annual expenditure

4. My annual income is about 3-5 times my annual expenditure

5. My annual income is more than 5 times my annual expenditure

10. Choose a statement which best describes your family situation 
1. I have dependents without income

2. I have dependents but they have sufficient individual income

3. I have no dependents and i am not a dependent

4. I am a dependent without income

5. I am a dependent but I have sufficient individual income

\section{Risk Tolerance}

1. Which word comes to mind when you think of "financial risk"?
1. Danger
2. Uncertainty
3. Indifference
4. Opportunity
5. Thrill

2. Compared to other people with the same financial and socioeconomic status, how would you rate your ability to tolerate the stress associated with important financial matters?
1. Very low
2. Low
3. Average
4. High
5. Very high

3. How do you feel about the following statement: "I can easily adapt to significant unexpected and unfavourable financial changes"?
1. Disagree
2. Slightly disagree
3. Neither agree or disagree
4. Slightly agree
5. Agree

4. All investment decisions involve the possibility of making money and a chance of losing all or a portion of the investment. When making an investment decision, which is more significant?

1. I would consider the potential loss first.

2. I would consider the potential loss somewhat more than the potential gain.

3. Both potential loss and gain are about the same to me.

4. I would consider the potential gain somewhat more than the potential loss.

5. I would consider the potential gain first.

5. You have just received a substantial sum of money. How would you invest it?

1. I would not invest it.

2. In something that offers moderate current income and has low risk

3. In something that offers high current income with moderate risk

4. In something that offers high total return (current income plus capital appreciation) with moderately high risk

5. In something that offers substantial capital appreciation with very high risk

6. Assuming that you are investing for the long-term, how would you feel if the value of your portfolio dropped 5\%?

1. I cannot tolerate any loss. Very uncomfortable.

2. I cannot tolerate this or any more loss. Quite uncomfortable.

3. I can tolerate this drop but not any more loss. Somewhat uncomfortable.

4. I can tolerate this drop and a little more loss. Comfortable.

5. I can tolerate this loss and more

7. Assuming that you are investing for the long-term, how would you feel if the value of your portfolio dropped $15 \%$ ?

1. I cannot tolerate any loss. Very uncomfortable.

2. I cannot tolerate this or any more loss. Quite uncomfortable.

3. I can tolerate this drop but not any more loss. Somewhat uncomfortable.

4. I can tolerate this drop and a little more loss. Comfortable.

5. I can tolerate this loss and more

8. Assuming that you are investing for the long-term, how would you feel if the value of your portfolio dropped $25 \%$ ?

1. I cannot tolerate any loss. Very uncomfortable.

2. I cannot tolerate this or any more loss. Quite uncomfortable.

3. I can tolerate this drop but not any more loss. Somewhat uncomfortable. 
4. I can tolerate this drop and a little more loss. Comfortable.

5. I can tolerate this loss and more

9. Assuming that you are investing for the long-term, how would you feel if the value of your portfolio dropped $50 \%$ ?

1. I cannot tolerate any loss. Very uncomfortable.

2. I cannot tolerate this or any more loss. Quite uncomfortable.

3. I can tolerate this drop but not any more loss. Somewhat uncomfortable.

4. I can tolerate this drop and a little more loss. Comfortable.

5. I can tolerate this loss and more

\section{Question for Unity Input}

The results of this questionnaire will be computed to yield a final "risk score" on a scale of 0 to 100 . In practice, however, the scores range from 20 to 80, with the average being 50. When the scores are graphed they follow the familiar bell-shaped curve of the Normal distribution (see below). About twothirds of all scores are between 40 and 60 .

What do you think your score will be?

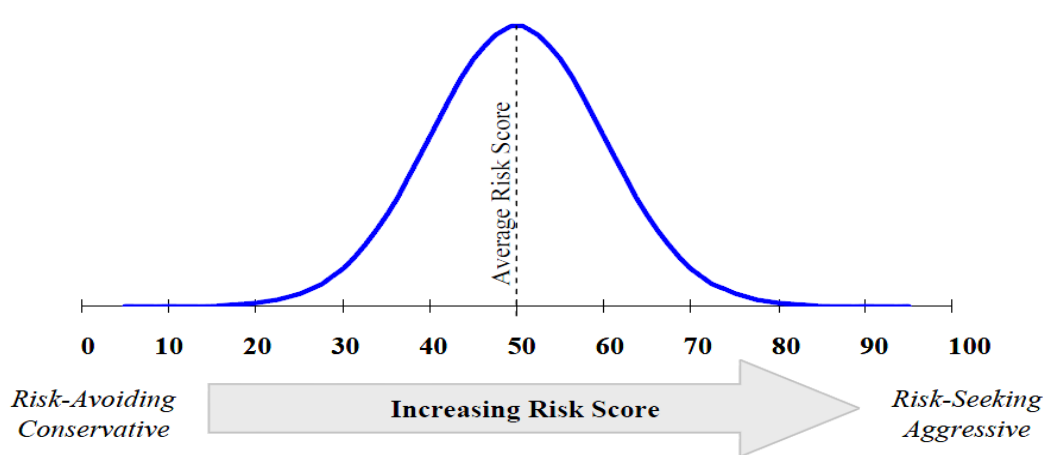

